UCRL-JC-119388

PREPRINT

CONF-950476-14

2D and 3D Ablation Front Hydrodynamic Instability Experiments on Nova

$$
\begin{aligned}
& \text { AROEHEO }
\end{aligned}
$$

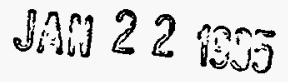

$$
\begin{aligned}
& \text { OSTI }
\end{aligned}
$$

B. A. Remington, M. M. Marinak, S. V. Weber, K. S. Budil,

O. L. Landen, S. G. Glendinning, S. W. Haan,

J. D. Kilkenny, R. J. Wallace, G. Dimonte

This paper was prepared for submittal to the 12th International Conference on Laser Interaction and Related Plasma Phenomena

Osaka, Japan

April 24-28, 1995

April 12, 1995

This is a preprint of a paper intended for publication in a journal or proceedings. Since changes may be made before publication, this preprint is made available with the understanding that it will not be cited or reproduced without the permission of the author. 


\section{DISCI.AIMER}

This document was prepared as an account of work sponsored by an agency of the United States Government. Neither the United States Government nor the University of ('alifornia nor any of their employees, makes any warranty, express or implied, or assumes any legal liability or responsibility for the accuracy. completeness, or usefulness of any information, apparatus, product, or process disclosed, or represents that its use would not infringe privately orned rights. Reference herein to any specific commercial products, process, or service by trade name, trademark, manufacturer, or otherwise, does not necessarily constitute or imply its endorsement, recommendation, or favoring by the linited States Ciovernment or the IIniversity of California. The views and opinions of authors expressed herein do not necessarily state or reflect those of the I'nited States Covernment thereof, and shall not be used for advertising or product endorsement purposes. 


\title{
2D and 3D Ablation Front Hydrodynamic Instability Experiments on Nova
}

\author{
B.A. Remington, M.M. Marinak, S.V. Weber, K.S. Budil, \\ O.L. Landen, S.W. Haan, J.D. Kilkenny, and R.J. Wallace
}

Lawrence Livermore National Laboratory, Livermore, CA 94550

\begin{abstract}
Single-mode experiments have been conducted on the Nova laser to examine the effect of perturbation shape on ablation front Rayleigh-Taylor growth. The perturbations investigated had the same magnilude wave vector $k=\left(k_{x}{ }^{2}+k_{y}\right)^{1 / 2}$ and the same initial amplitude. The shapes corresponded to $2 \mathrm{D} \lambda=50 \mu \mathrm{m}, 3 \mathrm{D}$ square $\mathrm{k}_{\mathrm{x}}=\mathrm{k}_{\mathrm{y}}$, and stretched $\mathrm{k}_{\mathrm{x}}=3 \mathrm{k}_{\mathrm{y}}$ perturbations. We observed that the 3D perturbations grew more than the $2 \mathrm{D}$ perturbation. Numerical simulations in $2 \mathrm{D}$ and $3 \mathrm{D}$ are in agreement, showing the most symmetric modes growing the largest.
\end{abstract}

Understanding the Rayleigh-Taylor (RT) instability is of critical importance to inertial confinement fusion (ICF) because large RT growth on imploding capsules can degrade implosion performance. In direct drive, nonuniformities in laser illumination imprint nonuniformities onto the capsule pusher ablation front. In indirect drive, residual capsule surface imperfections lead to perturbations at the ablation front. In both cases, the ablation front is RT unstable and perturbations grow. In the linear regime, the perturbation growth is exponential,

$$
\eta=\eta_{0} \mathrm{e}^{n}
$$

where $\eta$ represents perturbation amplitude and the growth rate $\gamma$ can be written approximately as (1-3)

$$
\gamma=[\mathrm{kg} /(1+\mathrm{kL})]^{1 / 2}-\beta \mathrm{kv}_{\mathrm{a}}
$$

Here $g$ is acceleration, $k=2 \pi / \lambda$ is perturbation wave vector, $L$ is the density gradient scale length, $\beta$ is a constant between 1 and 3 , and $v_{a}$ is ablation velocity. When the perturbation spatial amplitude is nonnegligible compared to its wavelength, the RT evolution enters the nonlinear regime. For semi-infinite, incompressible fluids, the bubble approaches its terminal velocity, corresponding to the buoyancy being exactly balanced by kinematic drag $(4,5)$. In this limit the bubble amplitude is just $\eta(t)=\int u_{B} d t$, with bubble velocity

$$
\mathrm{u}_{\mathrm{B}}=a(\mathrm{~g} \lambda)^{1 / 2} \text {, }
$$


where $a=0.23$ in $2 \mathrm{D}$ and 0.36 in $3 \mathrm{D}$, and we have assumed an Atwood number of 1 for simplicity. Notice that for the same perturbation wavelength (bubble diameter) $\lambda$, the bubble velocity is larger in $3 D$, since the kinematic drag per unit volume is less.

Perturbation growth is sensitive to perturbation shape. The transition to the nonlinear regime occurs approximately when the bubble velocity in the linear regime equals the nonlinear terminal bubble velocity, namely, when $\dot{\eta}_{\text {linear }}=\eta \eta$ $u_{B}$. Since $u_{B}$ is larger in 3D than in 2D from Eq. 3, the transition to the nonlinear regime happens later in $3 \mathrm{D}$. Hence, in $3 \mathrm{D}$ the linear regime exponential growth phase lasts longer and the asymptotic nonlinear growth rate is higher. Singlemode perturbations therefore are expected to grow larger in $3 \mathrm{D}$ than the equivalent perturbation in $2 \mathrm{D}$. This simple qualitative picture is supported by 3 rd order perturbation theory (6), recent work with a potential flow model (5), and full numerical simulations (7-9). Until recently, however, experiments in the ICF regime have been lacking due to their complexity. We present here new results of an experimental and computational investigation of $2 \mathrm{D}$ versus $3 \mathrm{D}$ single-mode perturbation growth at the ablation front in planar, indirectly driven foils (10). Recent advances in target fabrication (11) and diagnostic development (12) have made this experiment possible.

The experimental configuration is shown in Fig. la and is described in more detail elsewhere (13). A $750 \mu \mathrm{m}$ diameter, $60 \mu \mathrm{m}$ thick $\mathrm{CH}(\mathrm{Br})$ planar foil $\left(\mathrm{C}_{50} \mathrm{H}_{47} \mathrm{Br}_{3}, \rho=1.26 \mathrm{~g} / \mathrm{cm}^{3}\right)$ is mounted across a diagnostic hole on a $3 \mathrm{~mm}$ long, $1.6 \mathrm{~mm}$ diameter gold cyclindrical hohlraum. Eight of the 10 Nova laser beams (14) are used to generate a 3.3 ns low-adiabat, shaped drive, as shown in Fig. 1 b. Two 3 ns square beams are delayed relative to the drive and focused onto a Sc backlighter disk to generate $4.3 \mathrm{keV} \mathrm{He-} \alpha$-rays to back-illuminate the accerlating planar foil. Random phase plates with $5 \mathrm{~mm}$ diameter hexagonal elements are inserted as the last optic in the two backlighter lasers to generate a smooth $700 \mu \mathrm{m}$ diameter $\mathrm{x}$-ray spot. Typical timing of the backlighter lasers relative to the drive lasers is illustrated in Fig. 1b. On each laser shot, twodimensional gated $x$-ray images were obtained with a new flexible gated $x$-ray pinhole camera (12). Four pinhole images are obtained for each strip on the $\mathrm{MCP}$, and the interstrip delay was set to $700 \mathrm{ps}$. Half of the pinholes on each strip were filtered with $12.5 \mu \mathrm{m}$ of Ti to eliminate higher energy backlighter $\mathrm{x}$-rays such as from $\mathrm{He}-\beta$ and He- $\gamma$ transitions in Sc.

The foils were made using a new laser ablation technique to make molds in substrates of either kapton or mylar (11). We prepared perturbed foils all with the same magnitude wave vector $k=\left(k_{x}{ }^{2}+k_{y}{ }^{2}\right)^{1 / 2}$ and nominally the same amplitude. The "2D" foil (1D wave vector $k=k_{x}$ ) was a simple $\lambda=50 \mu \mathrm{m}$ sinusoid with initial amplitude $\eta_{0}=2.5 \mu \mathrm{m}$. One of the "3D" foils [2D wave vector $\left.k=\left(k_{x}, k_{y}\right)\right]$ corresponded to a "stretched" $k_{x}=3 k_{y}$ perturbation, and the other was a square $\mathrm{k}_{\mathrm{x}}=\mathrm{k}_{\mathrm{y}}$ mode. Characterization of the three foils was done using a contact radiography system, the resulting images of which are shown in Fig. 2a-c, and contact profilometry. The radiographs were converted to spatial amplitudes using 

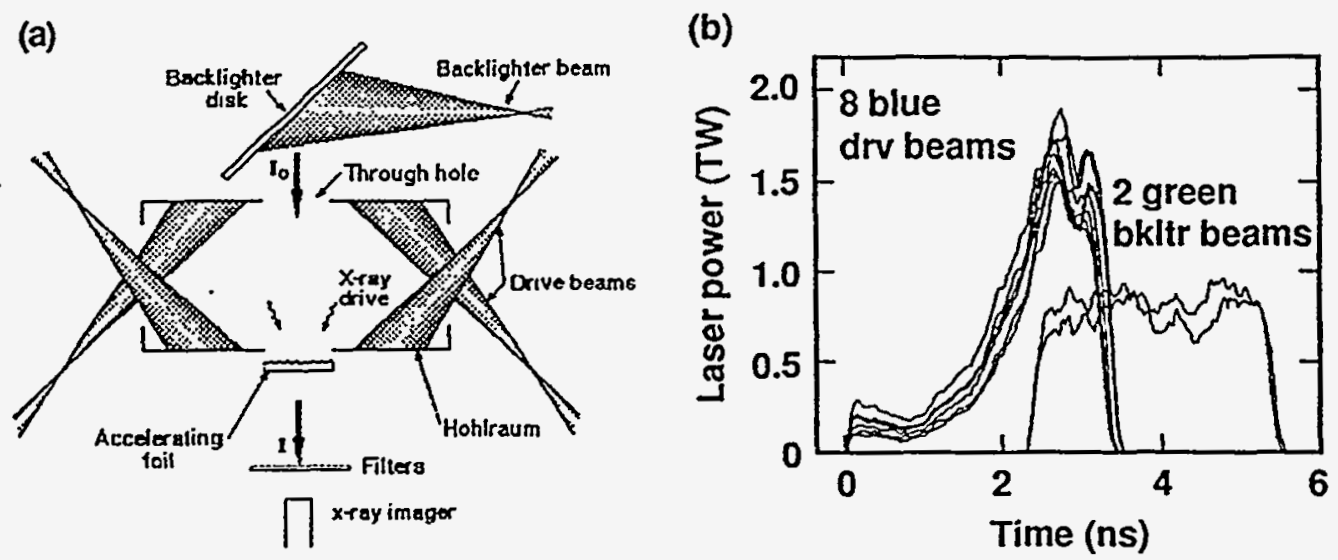

Figure 1. (a) The experimental configuration consists of a Au cylindrical hohlraum with the modulated $\mathrm{CH}(\mathrm{Br})$ foil mounted on the wall. The laser beams convert to $x$ rays in the hohlraum, which ablatively accelerate the foil. Two additional laser beams generate backlighter $x$ rays used for in-flight diagnosis of the foil. (b) Power versus time of the eight $0.351 \mu \mathrm{m}$ wavelength drive laser beams (curves starting at $\mathrm{t}=0$ ) and the two 0.528 $\mu \mathrm{m}$ wavelength backlighter beams (curves starting at $\mathrm{t}=2.4 \mathrm{~ns}$ ).

(a)

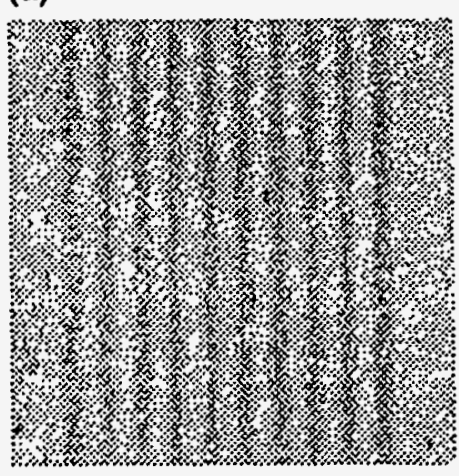

(d)

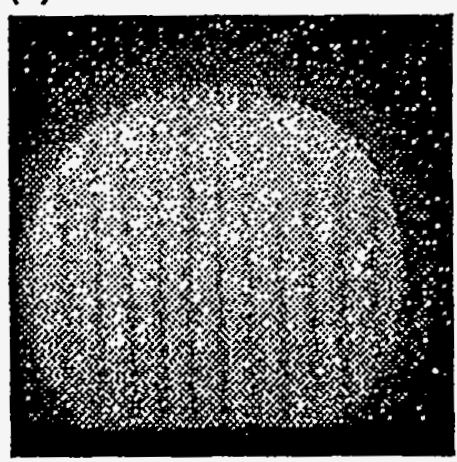

(b)

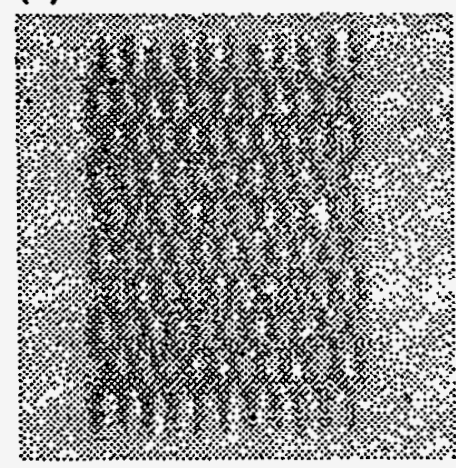

(e)

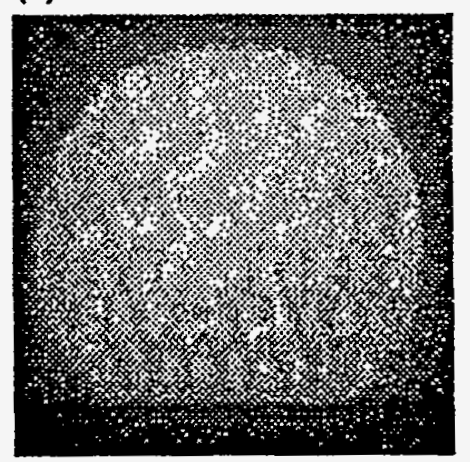

(c)

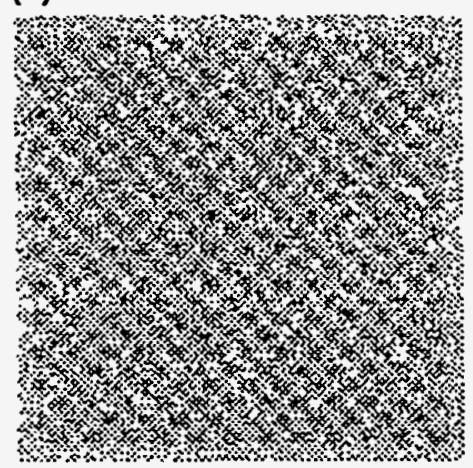

(f)

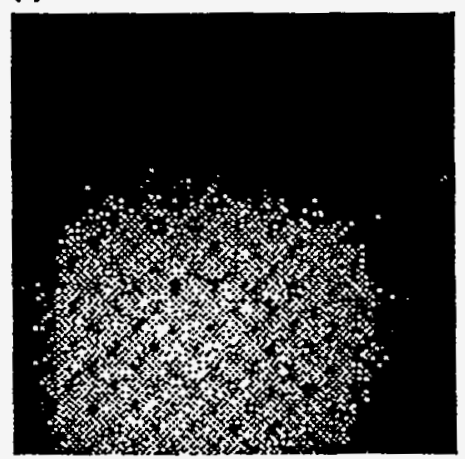

Figure 2. Contact radiographs of foils identical to those used in the Nova experiments are shown in (a)-(c). The perturbations correspond to (a) $2 D \lambda=50 \mu \mathrm{m}, \eta_{0}=2.5 \mu \mathrm{m}$, (b) $3 D$ $k_{x}=3 k_{y}: \lambda_{x}=53 \mu \mathrm{m}, \lambda_{y}=158 \mu \mathrm{m}, \eta_{0}=2.4 \mu \mathrm{m}$, and (c) $3 D k_{x}=k_{y}: \lambda_{x}=\lambda_{y}=71 \mu \mathrm{m}, \eta_{0}=2.7 \mu \mathrm{m}$. The corresponding images from the Nova shots taken at 4.3 ns are shown in (d)-(f). 
a step wedge of the same material, $\mathrm{CH}(\mathrm{Br})$. Images from the Nova shots at $4.3 \mathrm{~ns}$, which is near peak growth, are shown in Fig. 2d-f. The gated $x$-ray pinhole

camera for these.images was run at $8 \mathrm{x}$ magnification with $10 \mu \mathrm{m}$ pinholes, and $150 \mu \mathrm{m}$ Be filtering. - The backlighter was scandium at $4.3 \mathrm{keV}$.

Each image from the Nova shots is converted to $\ln$ (exposure) $\propto-\mathrm{OD}=$ $-\int \rho \kappa d z$. Hence, modulations in $\ln$ (exposure) correspond to modulations in foil areal density. The images are Fourier analyzed, and the amplitudes corresponding to the fundamental mode are extracted. A purely experimental demonstration of the effects of dimensionality on perturbation growth depends upon holding conditions between experiments identical. Two of our shots were done back to back on the same day, where the only change made between shots was the target ( $2 \mathrm{D} \lambda=50 \mu \mathrm{m}$ versus $3 \mathrm{D} \mathrm{k}_{\mathrm{x}}=3 \mathrm{k}_{\mathrm{y}}$ ). The total laser energy for these two shots was close (16.6 vs $15.8 \mathrm{~kJ}$ ), and the timing and filtering of the diagnostic were identical. The results for the evolution of the fundamental mode for these two shots is shown in Fig. 3a. The $3 \mathrm{D} \mathrm{k}_{\mathrm{x}}=3 \mathrm{k}_{\mathrm{y}}$ perturbation has clearly grown larger late in time in the nonlinear regime, as expected.

Shape effects on perturbation evolution can be examined under identical conditions with computer simulations. This is shown in Fig. 3b using the new 3D radiation-hydrodynamics code HYDRA (10). The perturbations, in order of decreasing peak growth, correspond to $\mathrm{k}_{\mathrm{x}}=\mathrm{k}_{\mathrm{y}}, \mathrm{k}_{\mathrm{x}}=2 \mathrm{k}_{\mathrm{y}}, \mathrm{k}_{\mathrm{x}}=3 \mathrm{k}_{\mathrm{y}}$, and $2 \mathrm{D} \lambda=50 \mu \mathrm{m}$. Our simulations clearly show that the most symmetric perturbations grow the largest, as has been reported by others (6-8). This is qualitatively in agreement with our experimental observations; quantitative comparisons are currently underway.

(a)

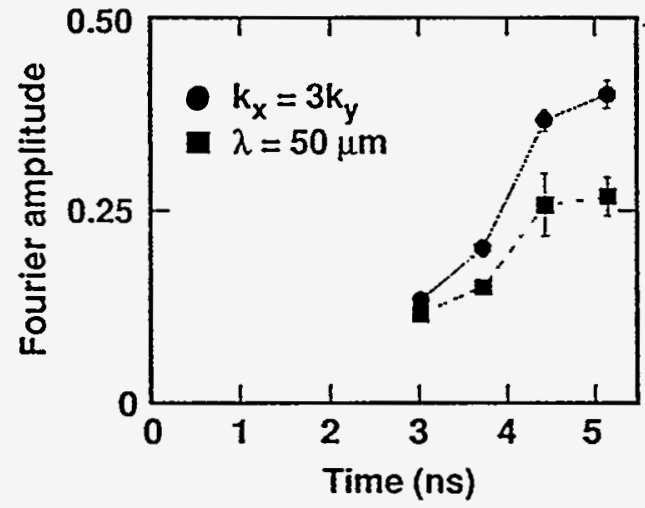

(b)

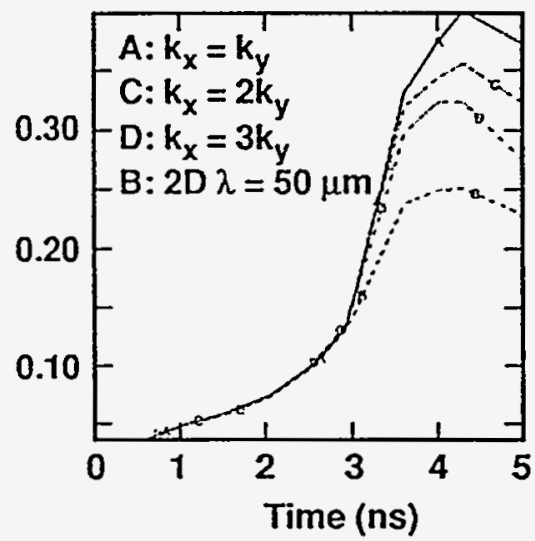

Figure 3. (a) Results of the evolution of the fundamental mode Fourier amplitude of $\ell n\left(\right.$ exposure) for the $3 D k_{x}=3 k_{y}$ (circles) and $2 D \lambda=50 \mu \mathrm{m}$ (squares) perturbations. The connecting lines are meant only to guide the eye. Experimental conditions were kept the same for these two shots to best illustrate the effect of shape on perturbation growth. The diagnostic setup was the same as described in Fig. 2. (b) Predicted Fourier amplitude of $\ell$ (exposure) from $3 D$ simulations for the evolution of four different perturbation shapes all with the same magnitude $k=\left(k_{x}{ }^{2}+k_{y}{ }^{2}\right)^{1 / 2}$ wavevector, for drive conditions slightly different from those of (a). The most symmetric $\left(k_{x}=k_{y}\right)$ mode is seen to grow the largest. 


\section{Acknowledgements}

We are pleased to ackowledge the assistance of S.G. Glendinning with software, invaluable discussions with D. Shvarts at the inception of this work, and the highly skilled Nova technical staff. *Work performed under the auspices of the U.S. Department of Energy by the Lawrence Livermore National Laboratory under contract number W-7405-ENG-48.

\section{References}

1. H. Takabe et al., Phys. Fluids 26, 2299 (1983); ibid 28, 3676 (1985).

2. D.H. Munro, Phys. Rev. A 38, 1433 (1988).

3. M. Tabak et al., Phys. Fluids B 2, 1007 (1990).

4. D. Layzer, Astrophys. J. 122, 1 (1955).

5. U. Alon et al., Phys. Rev. Lett. 72, 2867 (1994); ibid 74, 534 (1995).

6. J.W. Jacobs and I. Catton, J. Fluid Mech. 187, 329 (1988).

7. J.P. Dahlburg et al., Phys. Fluids B 5, 571 (1993).

8. J. Hecht et al., Phys. Fluids 6, 12 (1994).

9. D. Youngs, Lasers and Part. Beams 12, 725 (1994).

10. M.M. Marinak et al., submitted to Phys. Rev. Lett. (1995) and UCRL-JC-120191.

11. RJ. Wallace et al., ICF Quarterly Report 4, 79 (1994).

12. K.S. Budil et al., submitted to Rev. Sci. Instrum (1995).

13. B.A. Remington el al., Phys. Plasmas 2, 241 (1995).

14. J.D. Kilkenny et al., Rev. Sci. Instrum. 63, 4688 (1992). 


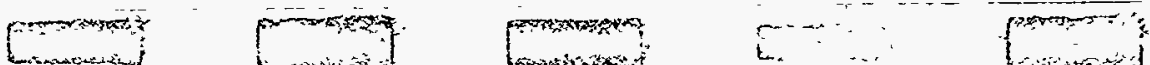




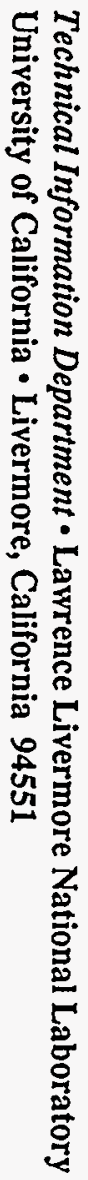

